\title{
Development of the Knee Quality of Life (KQoL-26) 26-item questionnaire: data quality, reliability, validity and responsiveness Andrew M Garratt ${ }^{1,2}$, Stephen Brealey*2, Michael Robling3, Chris Atwell3, Ian Russell ${ }^{4}$, William Gillespie ${ }^{5}$, David King ${ }^{6}$ for the DAMASK Trial Team
}

\begin{abstract}
Address: ${ }^{1}$ National Resource Centre for Rehabilitation in Rheumatology, Pb 23, Vinderen, 0319 Oslo, Norway, ${ }^{2}$ Department of Health Sciences, York Trials Unit, Seebohm Rowntree Building, University of York, Heslington, York YO10 5DD, UK, ${ }^{3}$ Department of Primary Care and Public Health, Cardiff University, Neuadd Meirionydd, Heath Park, Cardiff, CF14 4YS, UK, ${ }^{4}$ Institute of Medical and Social Care Research, Brigantia Building, Penrallt Road, University of Wales Bangor, Gwynedd, LL57 2AS, UK, 5Hull York Medical School, University of York, York, YO10 5DD, UK and ${ }^{6}$ X-ray Department, York Hospital, Wigginton Road, York, YO31 8HE, UK

Email: Andrew M Garratt - andrew.garratt@diakonsyk.no; Stephen Brealey* - sb143@york.ac.uk; Michael Robling - roblingmr@cardiff.ac.uk; Chris Atwell - atwellc@Cardiff.ac.uk; Ian Russell - ian.russell@bangor.ac.uk; William Gillespie - bill.gillespie@hyms.ac.uk;

David King - David.G.King@york.nhs.uk

* Corresponding author
\end{abstract}

Published: 10 July 2008

Health and Quality of Life Outcomes 2008, 6:48 doi:10.1 186/1477-7525-6-48

This article is available from: http://www.hqlo.com/content/6/1/48

(C) 2008 Garratt et al; licensee BioMed Central Ltd.

This is an Open Access article distributed under the terms of the Creative Commons Attribution License (http://creativecommons.org/licenses/by/2.0), which permits unrestricted use, distribution, and reproduction in any medium, provided the original work is properly cited.
Received: 18 June 2007

Accepted: 10 July 2008

\begin{abstract}
Background: This article describes the development and validation of a self-reported questionnaire, the KQoL-26, that is based on the views of patients with a suspected ligamentous or meniscal injury of the knee that assesses the impact of their knee problem on the quality of their lives.

Methods: Patient interviews and focus groups were used to derive questionnaire content. The instrument was assessed for data quality, reliability, validity, and responsiveness using data from a randomised trial and patient survey about general practitioners' use of Magnetic Resonance Imaging for patients with a suspected ligamentous or meniscal injury.
\end{abstract}

Results: Interview and focus group data produced a 40-item questionnaire designed for selfcompletion. 559 trial patients and 323 survey patients responded to the questionnaire. Following principal components analysis and Rasch analysis, 26 items were found to contribute to three scales of knee-related quality of life: physical functioning, activity limitations, and emotional functioning. Item-total correlations ranged from 0.60-0.82. Cronbach's alpha and test retest reliability estimates were $0.9 \mathrm{I}-0.94$ and $0.80-0.93$ respectively. Hypothesised correlations with the Lysholm Knee Scale, EQ-5D, SF-36 and knee symptom questions were evidence for construct validity. The instrument produced highly significant change scores for 65 trial patients indicating that their knee was a little or somewhat better at six months. The new instrument had higher effect sizes (range 0.86-I.I3) and responsiveness statistics (range I.50-2.13) than the EQ-5D and SF-36.

Conclusion: The KQoL-26 has good evidence for internal reliability, test-retest reliability, validity and responsiveness, and is recommended for use in randomised trials and other evaluative studies of patients with a suspected ligamentous or meniscal injury. 


\section{Background}

The recognition that randomised trials and similar forms of evaluative study should include patients' views about outcome has contributed to a huge growth in the development and testing of instruments that measure aspects of health and quality of life from the perspective of the patient [1]. The majority have been developed for specific patient populations [1], including patients with knee problems [2]. Several generic instruments that are suitable for application across different patient populations have also been evaluated in patients with knee problems [2], including the EQ-5D [3] and SF-36 [3-9], the two most widely evaluated measures of health status [1].

In selecting an instrument for a specific population or type of knee problem, it is important that consideration is given to both questionnaire content and the population in which it has been evaluated [10]. For an instrument to be considered appropriate for assessing the health outcomes of patients with a specific knee problem supporting evidence including reliability, validity and responsiveness must be available. Furthermore, if an instrument is to have content validity as a measure of health outcome that is relevant to patients, then its content should be based on the views of patients [10]. It follows that an instrument for patients' with knee problems must be based on an assessment of the impact of the condition on patient quality of life.

Sixteen instruments that are specific to knee problems with evidence for reliability and validity were identified by a recent systematic review [2]. Such a large number can confuse clinicians and researchers wishing to select an instrument for application in randomised trials and clinical practice. The lack of standardisation in the choice of instruments limits the generalisability of results. Furthermore, of the five instruments included in the review that were based on the views of patients in relation to instrument development and the content of individual questions, there was no instrument specific to ligamentous or meniscal injury of the knee that also had adequate evidence for reliability and validity. An instrument specific to ligamentous or meniscal injury of the knee that is based on the views of patients will have greater content validity and hence is more likely to be responsive to changes in quality of life that are important to patients. These measurement properties are a prerequisite for a patientreported instrument that is to be used in randomised trials and other forms of evaluative research.

This article describes the development of a knee-specific quality of life instrument based on the views of patients that has been used in a randomised trial and survey evaluating whether general practitioners (GPs) should have access to Magnetic Resonance Imaging (MRI) for patients with a suspected ligamentous or meniscal injury. The instrument was developed following in-depth interviews with patients and was assessed against criteria necessary for a self-reported instrument that will be used as an outcome measure within randomised trials and other forms of evaluative research including data quality, reliability, validity and responsiveness to change [10].

\section{Methods \\ Instrument development}

In-depth interviews were conducted with a pre-determined sample size of 35 patients to elicit how their knee injury affects their lives. Purposive sampling was used to select a stratified sample in relation to age, sex, severity, stage of management and condition - meniscal or ligamentous injuries. Interviews were conducted in two centres, Cardiff and York. They were audio-recorded and transcribed. Thematic analysis of the transcripts was undertaken by two researchers independently.

The resulting items were reviewed by the trial management group and piloted through a postal survey of 80 patients recruited from orthopaedic and physiotherapy departments at York Hospitals NHS Trust. Questionnaires were assessed for data quality including missing data and response frequencies. The questionnaire also included a question asking patients if they would be willing to attend an interview to discuss the questionnaire in more detail. These cognitive debriefing interviews conducted with twelve patients, were designed to assess whether they had any difficulties with particular items and if there were important areas not covered by the questionnaire.

Focus groups held with clinicians and patients in Cardiff and York were designed to assess content and face validity; the extent to which the items address the intended subject matter and whether relevant aspects of health and quality of life are adequately covered. The clinician focus groups included two GPs and three physiotherapists (Cardiff) and a GP, physiotherapist and consultant radiologist (York). The patient focus groups included three (Cardiff) and six patients (York). All focus groups followed a semistructured topic guide and patients completed the questionnaire.

\section{Data collection}

The instrument was evaluated concurrently within the randomised trial designed to evaluate whether GPs should have access to MRI for patients with a suspected ligamentous or meniscal injury. Patients completed a questionnaire at trial enrolment that also included the EQ-5D [11], SF-36 [12] and questions relating to knee symptoms. Patients who presented in general practice were eligible for inclusion in this trial if aged between 18 and 55 years inclusive and the GP was considering referral 
to an orthopaedic specialist for suspected meniscal or ligamentous injuries. The main exclusion criteria were that the patient needed urgent orthopaedic referral or had non-traumatic arthropathy, chronic instability of the knee, a previous MRI examination within the same episode of care, or previous surgical intervention (excluding diagnostic arthroscopy) on the same knee. These eligibility criteria were designed to help ensure a valid sample of patients were included in the trial. For example, the upper age limit of 55 years inclusive was used as this is when the onset of osteoarthritis occurs [13]. The injuries consistently referred to are those of the menisci, and cruciate or collateral ligaments $[14,15]$ so these are the type of patients GPs were asked to recruit. GP's also attended a two-hour education seminar that included the clinical assessment and management of patients with knee problems [16].

Questionnaires were also sent to patients invited to take part in a postal survey in Cardiff which comprised two cohorts: all recent GP referrals to the University Hospital of Wales and Llandough Hospital for MRI or orthopaedic consultation; and patients listed for an arthroscopy of the knee. These questionnaires included the Lysholm Knee Score [17], a widely used clinically-derived instrument for assessing ligament injuries of the knee. Postal reminders were sent at two and four weeks, and patients were contacted by telephone at six weeks.

\section{Statistical analysis}

Individual items were assessed for missing data. Principal component analysis (PCA) was used to identify interrelated variables or components of quality of life within the questionnaire items [18]. Items with poor component loadings were considered for removal. Items were further assessed for their contribution to the identified components with Rasch analysis [19], a form of item response theory (IRT) using the WINSTEPS programme [20]. IRT assumes that a measurement construct such as kneerelated quality of life can be represented by an ordered continuum that ranges from the minimum to maximum level of functioning. IRT models produce a hierarchy in which items are positioned according to the proportion of patients who report a limitation, and patients are positioned according to the total number of items in which they report a limitation [21]. Two mean square fit statistics assess the extent to which unpredicted responses to an item are given by patients whose position in the hierarchy as determined by their knee-related quality of life, is either close to the items position (Infit statistic) or far from the items position (Outfit statistic) in the hierarchy of items. It is generally recommended that the two fit statistics range from $0.7-1.3[21,22]$.
The instrument was assessed for internal consistency reliability using item-total correlation and Cronbach's alpha [10]. Test-retest reliability was assessed through a second questionnaire mailed to a random sample of every second patient taking part in the GP referral cohort of the Cardiff survey at two weeks. Patients reporting no change on the knee-specific transition question "Compared with 2 weeks ago, how is your knee now?" were included in the test-retest analysis $[10,23]$. To be acceptable for use in groups of patients the estimates of reliability should exceed $0.70[10,24]$.

The validity of the new instrument was assessed through comparisons with self-reported health status instruments and questions about knee symptoms. It was hypothesised that the new instrument would have a higher level of correlation of around 0.7 with the Lysholm Knee Score than the two generic instruments the EQ-5D and SF-36. Moderate levels of correlation of 0.5 were expected with the EQ-5D scores. Higher levels of correlation were expected for the EQ-5D items relating to mobility and pain than for self-care or anxiety-depression. Similarly, higher correlations in the range 0.5-0.7 were expected for the SF-36 scales of physical function, role-physical and bodily pain than for the scales of general health, vitality and mental health. Low to moderate levels of correlation above 0.4 were expected with patient responses to questions about number of days off work or normal activities in the past four weeks. It was hypothesised that instrument scores would reflect the different categories of symptoms in the form of a linear association, the highest and lowest KQoL26 scores being for patients having symptoms none of the time and all of the time respectively. It was hypothesised that patients who had or were considering changing job because of their knee would have lower scores than their counterparts.

Responsiveness was assessed on return of a follow-up questionnaire at six months for the trial patients. This questionnaire included a knee-specific health transition question "Compared with six months ago, how is your knee now?" which uses a 15 point scale from "a very great deal worse" to "a very great deal better". An improvement of a little or somewhat better has been defined as important [23]. Responsiveness was compared using effect sizes and responsiveness statistic. The former is equal to the mean change in score divided by the standard deviation of the baseline scores [10]. The latter is equal to the mean change in scores divided by the standard deviation of score differences in stable patients [25]. The larger the responsiveness statistic, the smaller the sample size needed for purposes of evaluation. The denominator was the standard deviation of the score changes for those patients in the test-retest analysis. 


\section{Ethics}

The study was designed to comply with the Declaration of Helsinki as adopted by the World Medical Association. Northern and Yorkshire Multi-Centre Research Ethics Committee reviewed and approved the study (reference number MREC/1/3/59).

\section{Results Instrument development}

Analysis of the interview transcripts produced a 38-item instrument which was scaled with three types of five-point adjectival scales of "totally limited/unable to do" to "not limited at all", "all of the time" to "none of the time" and "extremely" to "not at all". The instrument was piloted using a postal survey and 47 (58.8\%) were returned completed. Twelve questionnaires were also completed by patients attending the focus groups. With regards to missing data, when piloting the questionnaire 52 (88.1\%) patients completed all items. The focus groups and follow-up interviews confirmed the content and face validity of the questionnaire following the addition of two items about financial concerns and feelings of getting old relating to the knee problem.

\section{Data collection}

The 559 patients who took part in the trial completed the 40-item questionnaire. Of the 547 patients invited to take part in the Cardiff survey, 323 (59.0\%) returned a completed questionnaire. For the trial and survey patients the mean ages were $39.67(\mathrm{sd}=10.23)$ and $47.02(\mathrm{sd}=14.29)$ and the number of females was 204 (36.6\%) and 146 $(43.5 \%)$ respectively (Table 1$)$.

\section{Statistical analysis}

The majority of items have four or fewer missing responses in total, the mean number of missing responses being $0.12(\mathrm{sd}=0.67)$ with a range of 0 to $9(2.3 \%)$ patients that did not respond to a particular item. All forty items were completed by 751 (85.1\%) patients. The largest number of missing responses was eleven items for one patient which is just over one quarter of the items. Across the 0-4 response scale, means ranged from 1.05 to 3.47 for the items "avoiding turning, twisting or sideways movements" and "crossing the road" respectively. The former item had the highest floor effect of $35.4 \%$. The item "staying seated for 15 minutes" had the highest ceiling effect of $62.0 \%$. The spread of the item means indicates that items are measuring different degrees of kneerelated quality of life.

Principal component analysis gave five components with eigenvalues above 1.0 explaining $64.1 \%$ of the total variation between patients. The great majority of the items were making a strong contribution to the first component of the unrotated solution. Rotation served to identify clinically recognisable aspects of knee-related quality of life; the first, second and fourth components comprising items relating to physical functioning, activity limitations and emotional functioning respectively. The third and fifth components included six items relating to getting into or out of a lowered position and two items relating to bending and kneeling down respectively. The majority of these items and items within the physical functioning component had higher loadings within the first factor of the unrotated solution and the majority had loadings over 0.4 within the first component of the rotated solution. They were therefore assessed for their contribution to the hypothesised scale of physical functioning. As shown in Table 2, all items have component loadings above 0.5 , the great majority above 0.6.

Table 2 shows that for three scales the majority of items fit the Rasch model with Infit and Outfit statistics between 0.8 and 1.2 , the great majority within the recommended range $0.7-1.3$ [22]. This is further evidence that the instrument comprises three scales of knee-related quality of life. Within physical functioning, items 8 "bending down" and 17 "staying seated for two hours" have poor Infit and Outfit statistics which indicates that they do not fit the Rasch model very well and may not be sufficiently contributing

Table I: Patient characteristics

\begin{tabular}{|c|c|c|c|}
\hline \multicolumn{4}{|c|}{ Trial entry assessment ${ }^{\mathrm{a}}$} \\
\hline Characteristics & MRI referral $(n=279)$ & Orthopaedic referral $(n=274)$ & Survey patients $(n=323)$ \\
\hline Mean age, years (SD) & $40.1(9.9)$ & $39.1(10.5)$ & $47.0(14.3)$ \\
\hline \multicolumn{4}{|l|}{ Sex, n (\%) } \\
\hline Male & $185(66)$ & $164(69)$ & $177(56)$ \\
\hline Female & $94(34)$ & $109(40)$ & $146(44)$ \\
\hline \multicolumn{4}{|c|}{ Diagnostic category, n (\%) } \\
\hline Meniscal injury & $224(80)$ & $210(77)$ & \\
\hline Ligamentous injury & $87(3 I)$ & $82(30)$ & \\
\hline Other diagnosis & $5(2)$ & $9(3)$ & \\
\hline No diagnosis & $0(0)$ & $0(0)$ & \\
\hline
\end{tabular}

alnformation was not available for six patients. 
Table 2: Principal component analysis, item-total correlation, logit measure and fit statistics $(\mathrm{n}=\mathbf{5 5 9})$

\begin{tabular}{|c|c|c|c|c|c|c|}
\hline \multirow[b]{2}{*}{ Scale/item } & & \multirow[b]{2}{*}{ Component loadings } & \multirow[b]{2}{*}{ Item-total correlation } & \multirow[b]{2}{*}{ Logit measure ${ }^{a}$ (error) } & \multicolumn{2}{|c|}{ Fit statistics } \\
\hline & & & & & Infit MNSQ & Outfit MNSQ \\
\hline \multicolumn{7}{|c|}{ Physical functioning } \\
\hline 1 & Lifting heavy objects & .69 & .68 & $-0.15(0.08)$ & 1.00 & 1.05 \\
\hline 2 & Running & .62 & .60 & $2.69(0.07)$ & 1.18 & 1.17 \\
\hline 3 & $\begin{array}{l}\text { Walking on uneven } \\
\text { ground }\end{array}$ & .67 & .68 & $0.75(0.07)$ & 0.87 & 0.90 \\
\hline 4 & Walking five miles & .70 & .69 & $1.95(0.07)$ & 1.14 & 1.10 \\
\hline 5 & Walking one mile & .71 & .74 & $0.29(0.07)$ & 1.11 & 1.04 \\
\hline $6^{b}$ & Walking 100 yards & .68 & .72 & $-1.62(0.11)$ & 0.87 & 0.81 \\
\hline 7 & Crossing the road & .67 & .68 & $-2.25(0.14)$ & 0.92 & 0.81 \\
\hline $8^{b}$ & Bending down & .53 & .55 & $0.62(0.07)$ & 1.36 & 1.37 \\
\hline 9 & Kneeling down & .63 & .63 & $2.25(0.07)$ & 1.00 & 0.98 \\
\hline 10 & Standing for one hour & .71 & .72 & $0.52(0.07)$ & 1.09 & 1.07 \\
\hline II & $\begin{array}{l}\text { Standing for five } \\
\text { minutes }\end{array}$ & .66 & .66 & $-1.56(0.12)$ & 0.94 & 0.85 \\
\hline 12 & $\begin{array}{l}\text { Going up several } \\
\text { flights of stairs }\end{array}$ & .77 & .79 & $1.09(0.07)$ & 0.71 & 0.72 \\
\hline 13 & $\begin{array}{l}\text { Going up one flight of } \\
\text { stairs }\end{array}$ & .75 & .78 & $-0.43(0.08)$ & 0.71 & 0.73 \\
\hline 14 & $\begin{array}{l}\text { Going down several } \\
\text { flights of stairs }\end{array}$ & .75 & .75 & $0.88(0.07)$ & 0.78 & 0.79 \\
\hline 15 & $\begin{array}{l}\text { Going down one flight } \\
\text { of stairs }\end{array}$ & .73 & .75 & $-0.36(0.08)$ & 0.74 & 0.73 \\
\hline 16 & $\begin{array}{l}\text { Getting into a sitting } \\
\text { position }\end{array}$ & .67 & .68 & $-1.24(0.10)$ & 1.02 & 0.97 \\
\hline $17^{b}$ & $\begin{array}{l}\text { Staying seated for two } \\
\text { hours }\end{array}$ & .55 & .53 & $0.01(0.08)$ & 1.55 & 1.50 \\
\hline $18^{b}$ & $\begin{array}{l}\text { Staying seated for } 15 \\
\text { minutes }\end{array}$ & .58 & .59 & $-1.49(0.12)$ & 1.11 & 0.94 \\
\hline $19 b$ & $\begin{array}{l}\text { Getting up from a } \\
\text { sitting position }\end{array}$ & .65 & .67 & $-0.35(0.08)$ & 0.99 & 1.00 \\
\hline $20^{b}$ & $\begin{array}{l}\text { Getting in or out of } \\
\text { the bath or shower }\end{array}$ & .71 & .73 & $-0.55(0.08)$ & 0.89 & 0.89 \\
\hline 21 & $\begin{array}{l}\text { Getting in or out of } \\
\text { bed }\end{array}$ & .67 & .68 & $-1.06(0.09)$ & 0.92 & 0.96 \\
\hline \multicolumn{7}{|l|}{ Activity limitations } \\
\hline 22 & $\begin{array}{l}\text { Knee slowing you } \\
\text { down }\end{array}$ & .62 & .76 & $0.69(0.07)$ & 0.69 & 0.74 \\
\hline $23^{b}$ & $\begin{array}{l}\text { Avoid turning/ } \\
\text { twisting/sideways } \\
\text { moves }\end{array}$ & .57 & .56 & I.66 (0.07) & 1.23 & 1.40 \\
\hline 24 & $\begin{array}{l}\text { Interference with } \\
\text { travel }\end{array}$ & .56 & .71 & $-0.88(0.08)$ & 1.29 & 1.24 \\
\hline $25^{b}$ & $\begin{array}{l}\text { Interference with } \\
\text { sleep }\end{array}$ & .50 & .64 & $-0.72(0.07)$ & 1.38 & $1.4 \mathrm{I}$ \\
\hline 26 & $\begin{array}{l}\text { Interference with } \\
\text { work }\end{array}$ & .59 & .78 & $0.31(0.07)$ & 0.79 & 0.80 \\
\hline $27^{b}$ & $\begin{array}{l}\text { Interference with } \\
\text { hobbies, etc }\end{array}$ & .62 & .51 & I.52(0.07) & 1.30 & 1.27 \\
\hline $28^{b}$ & $\begin{array}{l}\text { Interference with } \\
\text { family life }\end{array}$ & .59 & .80 & $-0.46(0.07)$ & 0.66 & 0.65 \\
\hline 29 & $\begin{array}{l}\text { Interference with } \\
\text { social activities }\end{array}$ & .56 & .81 & $-1.11(0.08)$ & 0.80 & 0.77 \\
\hline 30 & $\begin{array}{l}\text { Interference with } \\
\text { doing errands }\end{array}$ & .53 & .80 & $-1.02(0.08)$ & 0.83 & 0.80 \\
\hline \multicolumn{7}{|c|}{ Emotional functioning } \\
\hline 31 & $\begin{array}{l}\text { Time spent thinking } \\
\text { about knee }\end{array}$ & .64 & .71 & $1.34(0.07)$ & 0.84 & 0.94 \\
\hline 32 & Angry or annoyed & .73 & .74 & $0.61(0.07)$ & 0.83 & 0.78 \\
\hline 33 & Downhearted and low & .78 & .80 & $-0.23(0.07)$ & 0.82 & 0.80 \\
\hline 34 & $\begin{array}{l}\text { Worried about knee } \\
\text { worsening }\end{array}$ & .78 & .73 & $0.97(0.07)$ & 0.90 & 0.85 \\
\hline
\end{tabular}


Table 2: Principal component analysis, item-total correlation, logit measure and fit statistics $(\mathbf{n}=\mathbf{5 5 9})$ (Continued)

\begin{tabular}{lllllll}
\hline $35^{\mathrm{b}}$ & & .68 & $-1.16(0.08)$ & 1.17 & 1.10 \\
36 & $\begin{array}{l}\text { Embarrassed or self- } \\
\text { conscious } \\
\text { Bad temper or }\end{array}$ & .62 & .76 & $-1.14(0.08)$ & 0.77 & 0.77 \\
37 & $\begin{array}{l}\text { grumpy } \\
\text { Frustrated }\end{array}$ & .69 & .75 & $0.38(0.07)$ & 0.76 \\
$38^{\mathrm{b}}$ & Worry about future & .79 & .73 & $0.64(0.07)$ & 0.90 & 0.74 \\
$39 \mathrm{~b}$ & Worry about money & .60 & .58 & $-1.03(0.09)$ & 1.62 & 1.58 \\
$40^{\mathrm{b}}$ & Think that you are & .52 & .39 & $-0.38(0.08)$ & 1.79 \\
& getting old & & & & 1.87 \\
\hline
\end{tabular}

a Logits of lower magnitude represent decreasing quality of life.

b Item removed from final version.

to the construct of physical functioning. Similarly, three items within activity limitations and two items within emotional functioning have poor fit statistics. Item 22 is borderline.

For the three scales, all but one of the item-total correlations are above 0.40 . Removal of items 6, 8, 17, 18, 19 and 20 from the physical functioning scale which includes those performing poorly in the Rasch analysis, gave final item-total correlations of $0.60-0.81$ and a Cronbach's alpha of 0.94. Removing four items from the activity limitations scale including those performing poorly in the Rasch analysis, gave final items-total correlations of $0.70-$ 0.82 and an alpha of 0.91 . Removing four items from the emotional functioning scale including those performing poorly in the Rasch analysis, gave final item-total correlations of $0.74-0.81$ and an alpha of 0.91 .

Of the 109 randomly selected patients from the GP referral cohort of the Cardiff survey, 86 (78.9\%) completed a two-week retest questionnaire. The intra-class correlations for the two sets of scores for the 27 patients stating that there was no change in their knee were 0.93, 0.87 and 0.80 for the physical functioning, activity limitations and emotional functioning scales respectively. These reliability estimates meet the criteria necessary for group level comparisons $[10,26]$.

Table 3: Correlation between KQoL-26 scores, EQ-5D, Lysholm Knee Score, SF-36 and days affected by knee problem ( $\mathrm{n}=559)$

\begin{tabular}{|c|c|c|c|}
\hline \multirow[b]{2}{*}{ Variable } & \multicolumn{3}{|c|}{ KQoL-26 scales } \\
\hline & Physical functioning & Activity limitations & Emotional functioning \\
\hline EQ-5D score & .54 & .49 & .50 \\
\hline Mobility & .52 & .49 & .35 \\
\hline Self-care & .35 & .31 & .21 \\
\hline Usual activities & .31 & .31 & .31 \\
\hline Pain/discomfort & .43 & .38 & .40 \\
\hline Anxiety/depression & .32 & .34 & .45 \\
\hline Lysholm Knee Score ${ }^{a}$ & .76 & .76 & .58 \\
\hline \multicolumn{4}{|l|}{ SF-36: } \\
\hline Physical functioning & .75 & .65 & .50 \\
\hline Role physical & .54 & .61 & .55 \\
\hline Bodily pain & .54 & .62 & .55 \\
\hline General health & .25 & .22 & .21 \\
\hline Vitality & .43 & .44 & .48 \\
\hline Social functioning & .57 & .66 & .60 \\
\hline Role emotional & .47 & .52 & .56 \\
\hline Mental health & .41 & .40 & .51 \\
\hline Physical Component Summary & .64 & .63 & .47 \\
\hline Mental Component Summary & .39 & .44 & .55 \\
\hline Days off work due to knee & .25 & .38 & .28 \\
\hline Days normal activity prevented & .38 & .46 & .43 \\
\hline
\end{tabular}

a Cardiff survey data $(n=323)$

All correlations are statistically significant $(p<0.01)$ 
The score distributions for the new instrument now referred to as the KQoL-26, are computed by summing the items where half or more are completed for the relevant scale and transforming to a 0-100 scale. The scores were approximately normal on a scale of $0-100$ where 100 is the best possible knee-related quality of life. Means scores were $59.1(\mathrm{sd}=18.8), 51.05(\mathrm{sd}=25.2)$ and $40.4(\mathrm{sd}=$ 21.4) for the physical functioning, activity limitations and emotional functioning scales respectively. Therefore the instrument has the potential to measure differences in knee-related quality of life in cross-sectional or longitudinal studies.

The results of the tests of validity are shown in Tables 3 and 4 . The correlations between KQoL-26 scores, the Lysholm, EQ-5D, SF-36 and knee-related questions are shown in Table 3. As hypothesised the highest correlations are with the Lysholm Knee Score. This is higher than that hypothesised which may reflect the high level of reliability of the new instrument $[10,26]$. As hypothesised, in general the KQoL-26 had the highest correlations with

Table 4: Mean (standard deviation) KQoL-26 scores ${ }^{\mathrm{a}}$ by responses to knee-related questions

\begin{tabular}{|c|c|c|c|c|c|c|}
\hline \multirow[t]{2}{*}{ Variable } & \multicolumn{2}{|c|}{ Physical functioning } & \multicolumn{2}{|c|}{ Activity limitations } & \multicolumn{2}{|c|}{ Emotional functioning } \\
\hline & $\mathrm{n}$ & mean $(s d)$ & $\mathrm{n}$ & mean $(s d)$ & $\mathrm{n}$ & mean (sd) \\
\hline \multicolumn{7}{|l|}{ Knee pain present during day: } \\
\hline None of the time & 7 & $71.52(19.44)$ & 7 & $80.00(23.98)$ & 7 & $73.71(21.27)$ \\
\hline Some of the time & 305 & $65.91(16.93)$ & 306 & $60.74(21.97)$ & 306 & 47.55 (19.78) \\
\hline All of the time & 237 & $49.93(17.50)$ & 235 & 37.43 (22.69) & 237 & $30.08(18.65)$ \\
\hline \multicolumn{7}{|l|}{ Knee pain present at night: } \\
\hline None of the time & 64 & $74.5 \mathrm{I}(14.47)$ & 64 & $73.75(18.90)$ & 64 & $54.16(22.13)$ \\
\hline Some of the time & 345 & $60.47(17.54)$ & 344 & $53.09(23.31)$ & 346 & $42.62(20.03)$ \\
\hline All of the time & 144 & 48.92 (I8.52) & $|4|$ & $35.57(22.75)$ & $|4|$ & $28.55(18.87)$ \\
\hline \multicolumn{7}{|l|}{ Knee pain worse on movement: } \\
\hline None of the time & 12 & $72.15(18.63)$ & 12 & $69.72(25.27)$ & 12 & $65.67(23.85)$ \\
\hline Some of the time & 264 & $65.62(17.97)$ & 263 & $59.84(22.56)$ & 265 & $46.02(20.89)$ \\
\hline All of the time & 273 & $52.25(17.32)$ & 273 & $41.65(24.30)$ & 273 & $33.70(19.48)$ \\
\hline \multicolumn{7}{|l|}{ Knee stiff in morning: } \\
\hline None of the time & 110 & $69.18(17.32)$ & 110 & $64.92(23.01)$ & 110 & $49.08(21.64)$ \\
\hline Some of the time & 237 & $60.45(18.07)$ & 237 & $52.63(23.84)$ & 237 & $41.59(21.03)$ \\
\hline All of the time & 201 & $52.21(18.15)$ & 201 & $41.62(24.22)$ & 201 & $33.79(19.81)$ \\
\hline \multicolumn{7}{|l|}{ Duration of morning stiffness: } \\
\hline Less than I hour & 63 & $61.23(18.20)$ & 63 & $53.40(23.55)$ & 63 & $42.31(20.46)$ \\
\hline I to 2 hours & 112 & $50.52(17.55)$ & 112 & $39.65(23.85)$ & 112 & 32.84 (19.09) \\
\hline Over 2 hours & 268 & $49.85(18.11)$ & 268 & $38.49(25.07)$ & 268 & $30.43(21.06)$ \\
\hline \multicolumn{7}{|l|}{ Knee given way when walking: } \\
\hline Never & 166 & $65.36(18.76)$ & 166 & $59.80(24.13)$ & 166 & $47.27(20.83)$ \\
\hline Over three months ago & 42 & 67.74 (18.77) & 42 & $57.86(25.47)$ & 42 & $45.43(22.40)$ \\
\hline One to three months ago & 48 & $61.97(18.41)$ & 48 & $54.90(24.70)$ & 48 & $39.58(21.38)$ \\
\hline In the last month & 293 & $53.80(17.57)$ & 293 & 44.27 (24.09) & 293 & $35.77(20.6 \mathrm{I})$ \\
\hline \multicolumn{7}{|l|}{ Painful inability to straighten knee: } \\
\hline Never & 135 & $66.61(16.75)$ & 135 & $59.0 I(24.7 I)$ & 135 & $47.68(22.24)$ \\
\hline Over three months ago & 39 & $66.54(17.39)$ & 39 & $59.49(24.70)$ & 39 & $45.95(21.22)$ \\
\hline One to three months ago & 48 & 64.55 (17.98) & 48 & $46.38(23.60)$ & 48 & $41.46(22.32)$ \\
\hline In the last month & 324 & $54.33(18.64)$ & 324 & $45.90(24.52)$ & 324 & $36.59(20.09)$ \\
\hline \multicolumn{7}{|l|}{ Presence of knee swelling: } \\
\hline Never & 118 & $66.41(17.83)$ & 117 & $61.85(24.14)$ & 118 & $47.97(21.70)$ \\
\hline Over three months ago & 35 & $72.95(15.87)$ & 35 & $68.71(20.52)$ & 35 & $54.51(21.17)$ \\
\hline One to three months ago & 58 & $60.83(17.61)$ & 58 & $51.90(26.40)$ & 58 & $38.79(20.79)$ \\
\hline In the last month & 333 & 55.06 (18.09) & 333 & $45.32(23.64)$ & 334 & $36.55(20.08)$ \\
\hline \multicolumn{7}{|l|}{ Changed job due to knee: } \\
\hline No & 506 & $58.79(16.17) \mathrm{NS}$ & 505 & $51.02(24.93) \mathrm{NS}$ & 507 & $40.47(21.28) \mathrm{NS}$ \\
\hline Yes & 18 & $57.13(18.68)$ & 18 & $41.67(25.14)$ & 18 & $36.67(20.04)$ \\
\hline \multicolumn{7}{|c|}{ Considering job change due to knee: } \\
\hline No & 486 & $59.54(18.92) \mathrm{NS}$ & 485 & $51.91(24.85)$ & 487 & $41.41(20.93)$ \\
\hline Yes & 27 & $53.55(\mid 8.4 I)$ & 27 & $36.11(20.95)$ & 27 & $28.15(19.80)$ \\
\hline
\end{tabular}

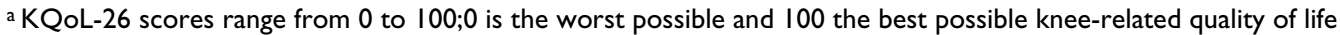
All results are statistically significant $(p<0.01)$ unless indicated; NS not significant 
aspects of the EQ-5D and SF-36 relating to physical health. The KQoL-26 physical functioning and activity limitations had the largest correlations with the EQ-5D mobility and pain items. As expected the emotional functioning scale had the largest correlation with the EQ-5D anxiety and depression item. The KQoL scales had a similar moderate level of correlation with EQ-5D index scores. The KQoL-26 physical functioning and activity limitations scales had the largest correlations with the SF-36 scales of physical functioning, social functioning, bodily pain and role-physical. The emotional functioning scale had the largest correlations with social functioning and role-emotional. This KQoL scale also had the highest correlation with the SF-36 mental component summary scores, the other two scales having higher correlations with the physical component summary scores. The correlations with the number of days off work and on which normal activity was prevented because of the knee were of a low to moderate level. As expected, the activity limitations scale scores had the highest level of correlations with responses to these two questions.

Table 4 shows the results of the tests of validity in comparison to knee symptoms and change of job. The results are statistically significant for 26 of the 30 tests. The sample sizes are relatively small for those patients who have changed or are considering changing their job because of their knee, however three of the results are statistically significant, the largest differences being found for the activity limitations scale.
Of the 559 trial patients sent a six month questionnaire, $472(84.4 \%)$ responded. Of these, 65 indicated that they had undergone an improvement of "a little better or somewhat better" on the knee-related health transition question. Table 5 shows the score changes, effect sizes and responsiveness index for these patients. With the exception of four SF-36 scale scores, all the instruments show a significant score improvement at six months. The KQoL26 shows an improvement of 16.41, 23.38 and 23.46 points on scales of physical functioning, emotional functioning and activity limitations respectively. The KQoL-26 has the three highest effect sizes and responsiveness statistics.

\section{Discussion}

There are a large number of knee-specific instruments for measuring the health status and outcomes of patients with knee problems. Few have been adequately evaluated for the measurement properties deemed necessary for selfreported measures of health and quality of life [2]. Only three of the five instruments that incorporate the views of patients have been adequately evaluated for reliability and validity. Of these, the Knee Pain Scale [27] and Oxford Knee Score [28] were developed in patients with osteoarthritis and there is limited empirical evidence for the internal construct validity, including the results of factor and principal component analysis, of the scales of the Knee Injury and Osteoarthritis Outcome Score $[2,29]$. The WOMAC is another instrument that has had wide application, but for patients with osteoarthritis and was not

Table 5: Mean (standard deviation) scores and responsiveness index for trial patients $(n=65)$ who have undergone a knee-related health improvement of "a little better or somewhat better" at six months

\begin{tabular}{|c|c|c|c|c|c|}
\hline Variable & Baseline & Six months & Change & Effect size ${ }^{a}$ & Responsiveness index ${ }^{b}$ \\
\hline \multicolumn{6}{|l|}{ KQoL-26: } \\
\hline Physical functioning & 57.08 (18.99) & $73.49(15.44)$ & $16.4 \mid(\mid 6.95)^{* *}$ & 0.86 & 2.13 \\
\hline Activity limitations & $51.15(25.86)$ & $74.62(16.96)$ & $23.46(20.19)^{* *}$ & 0.91 & 1.86 \\
\hline Emotional functioning & $40.92(20.73)$ & $64.31(19.84)$ & $23.38(15.46)^{* *}$ & 1.13 & 1.50 \\
\hline EQ-5D & $0.60(0.26)$ & $0.72(0.13)$ & $0.12(0.24)^{* *}$ & 0.46 & 0.51 \\
\hline \multicolumn{6}{|l|}{ SF-36: } \\
\hline Physical functioning & $54.77(25.87)$ & $69.89(19.54)$ & $15.12(2 \mid .33)^{* *}$ & 0.58 & 1.12 \\
\hline Role physical & $54.90(32.09)$ & $69.33(23.38)$ & $14.42(26.86)^{* *}$ & 0.44 & 0.86 \\
\hline Bodily pain & $46.17(26.67)$ & $63.40(19.62)$ & $17.23(21.71)^{* *}$ & 0.65 & 0.78 \\
\hline General health & $69.57(18.08)$ & $66.08(19.97)$ & $-3.49(14.60)$ & -0.19 & 0.23 \\
\hline Vitality & $52.40(18.84)$ & $53.94(18.90)$ & $1.54(18.05)$ & 0.08 & 0.08 \\
\hline Social functioning & $66.54(27.07)$ & $78.08(20.61)$ & II.54 (24.44)** & 0.42 & 0.93 \\
\hline Role emotional & $77.18(31.12)$ & 85.77 (19.02) & $8.59(27.24)^{*}$ & 0.28 & 0.59 \\
\hline Mental health & $70.38(19.21)$ & $70.92(16.81)$ & $0.54(14.42)$ & 0.03 & 0.03 \\
\hline Physical Summary & $38.90(10.52)$ & $44.63(8.74)$ & $5.73(9.4 I)^{* *}$ & 0.55 & 1.06 \\
\hline Mental Summary & $48.74(12.25)$ & $49.32(10.17)$ & $0.58(9.71)$ & 0.05 & 0.09 \\
\hline
\end{tabular}

a $E S=$ Mean change in score divided by the standard deviation of baseline score

$\mathrm{b} \mathrm{RI}=$ Mean change in score divided by the standard deviation of score changes in stable subjects

Asterisks denote statistical significance: ${ }^{*} p<0.05 ;{ }^{* *} p<0.01$ 
developed solely for knee problems [30]. Therefore the instrument has less content validity as a measure of the effect of a patient's knee problem on their quality of life and may also be less responsive than an instrument that is specific to the knee [10].

The KQoL-26 is a self-reported questionnaire for assessing knee-related quality of life that is based on the views of patients and satisfies the requirements of a patientreported outcome measure that is suitable for randomised trials [10]. The instrument has undergone a more extensive evaluation than the great majority of instruments described in a recent systematic review [2]. Based on patient interviews, focus groups, piloting and follow-up interviews, instrument development ensured that the views of patients with knee problems formed the basis of item construction. Therefore the KQoL-26 has high content validity as a measure of knee-related quality of life. The instrument was then evaluated for reliability, construct validity and responsiveness to change in a large sample of patients with a suspected ligamentous or meniscal injury. The result is an instrument that has the measurement characteristics necessary for a patientreported outcome measure for use in evaluation [10].

The response rate to the Cardiff survey of $59.0 \%$ was considerably lower than the trial where patients had a stronger incentive to return a completed questionnaire. The KQoL-26 takes patients around five minutes to complete which is acceptable for an instrument that is to be used alongside other instruments within a questionnaire booklet for assessing health outcomes. The low levels of missing data for the 26 items are further evidence that the instrument is acceptable to patients as a self-reported postal questionnaire. Scale scores were computable for 557 (99.6\%) of the 559 trial patients who returned a baseline questionnaire. The results of principal component analysis and Rasch analysis are strong evidence that the 26-items contribute to three knee-related quality of life scales: physical functioning, activity limitations and emotional functioning. The final item-total correlations ranged from 0.6 to 0.82 , which are within widely accepted standards $[10,24,26]$. The estimates for internal and testretest reliability are all above 0.80 which suggests that the instrument is suitable for use in applications involving groups of patients including randomised trials. Physical functioning, the most important scale for capturing variation between patients and the most responsive according to the responsiveness index, may be appropriate for use by individual patients, including clinical practice [10].

Twelve of the 16 knee-specific instruments included in a systematic review have been tested for test-retest reliability, the majority of which produced test-retest correlations over 0.7 [2]. The present study asked patients to complete a health transition question so that only those patients stating that there had been no change in their knee condition in the two weeks between administrations were included in the test-retest analysis. None of the test-retest studies reported in the review used transition questions but the great majority had shorter times between test and retest questionnaires of between 1 and 14 days to ensure that the patients' knee condition had not changed [2]. The reliability estimates for the KQoL-26 are acceptable and over 0.8 , the lowest being for the emotional functioning scale which might be expected given the content of the knee transition question. Higher test-retest estimates might have been produced with three transition questions which directly related to the content of the three KQoL-26 scales.

The tests of responsiveness also followed the application of a criterion based on a health transition question. Patients were selected who stated that they had undergone an improvement of a little or somewhat better on a widely used transition question [23]. In contrast to tests of responsiveness of following treatment previously used to assess knee-specific instruments [2], such a criterion has the advantage that it is patient-reported and hence is designed to determine the level of change that is of importance to them. Using the criterion of treatment of known efficacy may show which instrument is the most responsive in relation to existing interventions, but the most common application of patient-reported outcome measures is in the evaluation of new interventions including the randomised comparison with existing interventions which will produce more marginal gains in terms of clinical effectiveness. Smaller levels of change or differences in patient outcomes between interventions are of greater relevance and hence it is important that instruments are responsive to what patients' perceive to be small levels of change.

The results of comparisons with other instruments and knee-related questions are evidence for the validity of the KQoL-26. The high level of correlation with the Lysholm Knee Score and moderate to high levels of correlation with EQ-5D and SF-36 scores are evidence that the instrument is measuring the effects of patient knee problems across the different aspects of health and quality of life assessed by these instruments. In particular, the highest correlations with these instruments were found for the KQoL-26 scales that we would expect to have the greatest association. For example, of the three KQoL-26 scales, physical functioning had highest correlations with the EQ-5D scores for mobility and SF-36 physical functioning scores and physical component summary scale. Activity limitations had the highest correlations with the SF-36 social functioning scores. This scale also produced the highest correlations with the number of days that work 
and normal activity was prevented. Emotional functioning had the highest correlations with EQ-5D scores for anxiety/depression and mental component summary scores. This scale also had the highest correlation of all with the SF-36 scale of role-emotional.

Nine existing knee instruments have been correlated with the SF-36 for purposes of assessing validity [2]. The range of the correlations found between the KQoL-26 and the SF-36 scales was generally higher than that found for existing instruments. In common with the majority of these instruments, the highest correlations were found between the KQoL-26 and the SF-36 scale of physical functioning. The Edinburgh Knee Function Scale [31], Knee Outcome Survey Activities of Daily Living Scale [32] and Oxford Knee Score [28] are the only instruments that based on the evidence included in this review, had correlations over 0.7 with the SF-36 physical functioning scale. Only the Oxford Knee Score had a larger correlation of 0.78 which was in a postoperative group; correlations for the preoperative group were more modest. In contrast to the KQoL-26, none of the review instruments had correlations over 0.5 with the mental health and role-emotional scales of the SF-36. This shows the importance of the KQoL-26 emotional functioning scale which had the largest correlations with these two SF-36 scales. Moreover, none of the review instruments had such consistently high correlations with the SF-36 scales of social functioning and role-physical as the KQoL-26 scale of activity limitations. This is evidence that the KQoL-26 has evidence for validity that exceeds that for existing knee instruments.

KQoL-26 scores were also significantly related to knee symptoms, activity limitations and work limitations. Large differences were found for the emotional functioning scale, an aspect of quality of life not covered by existing knee-specific instruments [2]. This is further evidence that the new instrument is assessing the broad impact on patient quality of life.

Finally, the three KQoL-26 scales produced highly significant score changes in patients who had what is recognised to be an important improvement on a self-reported kneerelated health transition question at six months [24]. The three scales scores were more responsive than the EQ-5D and SF-36 scales, particularly with respect to emotional functioning. Together with the evidence for the reliability and validity of the instrument, this further underpins the use of the KQoL-26 as a primary outcome measure within randomised trials.

\section{Conclusion}

The KQoL-26 has good evidence for data quality, reliability, validity and responsiveness to important changes in health. The KQoL-26 is recommended as an instrument that assesses aspects of health and quality of life that are important to patients with ligamentous or meniscal injuries.

\section{Competing interests}

The authors declare that they have no competing interests.

\section{Authors' contributions}

AMG conceived and designed the study, conducted the analysis and drafted the manuscript. SB contributed to the design of the study, acquired ethical approval, collected data, and commented on the manuscript. MR contributed to the design of the study, acquired ethical approval, collected data, and commented on the manuscript. CA collected data, contributed to analysis of data from patient interviews and focus groups, and commented on the manuscript. IR contributed to the design of the study and commented on the manuscript. WG contributed to the design of the study and commented on the manuscript. DK contributed to the design of the study and commented on the manuscript. All authors read and approved the final manuscript.

\section{Acknowledgements}

We thank the UK Medical Research Council for funding. The list of contributors to the study can be found at http://www.york.ac.uk/healthsciences/ centres/trials/damask/contributros damask.htm. We are indebted to the patients responding to the questionnaire and especially those patients (and clinicians) who participated in the interviews and focus groups.

\section{References}

I. Garratt AM, Schmidt L, Mackintosh A, Fitzpatrick R: Quality of life measurement: bibliographic study of patient assessed health outcome measures. BM] 2002, 324:14|7-14|9.

2. Garratt AM, Brealey S, Gillespie W: Patient-assessed-assessed health instruments for the knee: a structured review. Rheumatology (Oxford) 2004, 43:|4|4-| 423.

3. Hollingworth W, Mackenzie R, Todd CJ, Dixon AK: Measuring changes in quality of life following magnetic resonance imaging of the knee: SF-36, EuroQol or Rosser index? Qual Life Res 1995, 4:325-334.

4. Dunbar MJ, Robertsson O, Ryd L, Lidgren L: Appropriate questionnaires for knee arthroplasty. Results of a survey of $\mathbf{3 6 0 0}$ patients from The Swedish Knee Arthroplasty Registry. J Bone Joint Surg [Br] 200I, 83:339-44.

5. Jette DU, Jette AM: Physical therapy and health outcomes in patients with knee impairments. Phys Ther 1996, 76: I I78-I I87.

6. Shapiro ET, Richmond JC, Rockett SE, McGrath MM, Donaldson WR: The use of a generic, patient-based health assessment (SF36) for evaluation of patients with anterior cruciate ligament injuries. Am J Sports Med 1996, 24:196-200.

7. Kiebzak GM, Campbell M, Mauerhan DR: The SF-36 general health status survey documents the burden of osteoarthritis and the benefits of total joint arthroplasty: but why should we use it? Am J Manag Care 2002, 8:463-474.

8. Lingard EA, Katz JN, Wright RJ, Wright EA, Sledge CB: Validity and responsiveness of the Knee Society Clinical Rating System in comparison with the SF-36 and WOMAC. J Bone Joint Surg [Am] 200I, 83: 1856.

9. Bellamy N, Buchanan WW: A preliminary evaluation of the dimensionality and clinical importance of pain and disability in osteoarthritis of the hip and knee. Clin Rheum 1986, 5:23I-4I.

10. Fitzpatrick R, Davey C, Buxton MJ, Jones DR: Evaluating patientbased outcome measures for use in clinical trials. Health Technol Assess 1998, 2(14): 1-74. 
II. Brooks R, EuroQol Group: EuroQol: the current state of play. Health Policy 1996, 37:53-72.

12. Ware JE, Kosinski M, Dewey JE: How to score Version 2 of the SF-36 Health Survey. Lincoln, QualityMetric Incorporated 2000.

13. Beard SM, Perez I, Touch S, Bickerstaff D: Magnetic Resonance Imaging (MRI) in the Management of Knee Disorders. Sheffield: Trent Institute for Health Services Research, Universities of Leicester, Nottingham and Sheffield. Guidance Note for Purchasers 1999.

14. International Statistical Classification of Diseases and Related Health Problems. 10th edition. World Health Organisation; 1992:642-643.

15. McAlindon TE, Cooper C, Kirwan JR, Dieppe PA: Knee pain and disability in the community. BrJ Rheumatol 1992, 31:189-192.

16. Brealey SD, Atwell C, Bryan S, Coulton S, Cox H, Cross B, Fylan F, Garratt A, Gilbert FJ, Gillan MG, Hendry M, Hood K, Houston H, King D, Morton V, Orchard J, Robling M, Russell IT, Torgerson D, Wadsworth V, Wilkinson C: The DAMASK trial protocol: a pragmatic randomised trial to evaluate whether GPs should have direct access to MRI for patients with suspected internal derangement of the knee. BMC Health Serv Res 2006, 6:133.

17. Lysholm J, Gillquist J: Evaluation of knee ligament surgery results with special emphasis on use of a scoring scale. Am J Sports Med 1982, 10:150-154.

18. Jolliffe IT: Principal component analysis. New York, SpringerVerlag; 1986

19. Andrich D: Rasch models for measurement. Newbury CA, Sage Publications; 1988.

20. Linacre JM, Wright BD: A User's Guide to WINSTEPS BIGSTEPS: Rasch-Model Computer Programs. MESA Press; 2000.

21. Ryser L, Wright BD, Aeschlimann, Mariacher-Gehler S: A new look at the Western Ontario and McMaster Universities Osteoarthiritis Index using Rasch Analysis. Arthritis Care and Research 1999, 1 2:331-335.

22. Wright BD: Reasonable mean-square fit values. In Rasch measurement transactions. Part 2 Edited by: Wright BD, Linacre JM. Chicago, MESA; 1996:370.

23. Juniper EF, Guyatt GH, Willan A, Griffith LE: Determining a minimal important change in a disease-specific quality of life questionnaire. J Clin Epidemiol 1994, 47:81-87.

24. Nunnally JC, Bernstein IH: Psychometric theory. 3rd edition. New York, McGraw-Hill; 1994.

25. Guyatt G, Walter S, Norman G: Measuring change over time: assessing the usefulness of evaluative instruments. J Chon Dis 1987, 40:171-178.

26. Streiner GL, Norman RD: Health measurement scales: A practical guide to their development and use. 3rd edition. Oxford, Oxford University Press; 2003.

27. Rejeski WJ, Ettinger WH, Shumaker S, Heuser MD, James P, Monu J, Burns $R$ : The evaluation of pain in patients with knee osteoarthritis: the Knee Pain Scale. J Rheumatol 1995, 22: I I 24- I I 29.

28. Dawson J, Fitzpatrick R, Murray D, Carr A: Questionnaire on the perception of patients about total knee replacement. J Bone Joint Surg [Br] 1998, 80-B:63-69.

29. Roos EM, Roos HP, Ekdahl C, Lohmander LS: Knee Injury and Osteoarthritis Outcome Score (KOOS) - validation of a Swedish version. Scand J Med Sci Sports 1998, 8:439-448.

30. Bellamy N, Buchanan WW: A preliminary evaluation of the dimensionality and clinical importance of pain and disability in osteoarthritis of the hip and knee. Clin Rheum 1986, 5:23|-24|.

31. Leigh Brown AP, Kennedy ADM, Grant AM, Campbell J, Macnicol MF, Torgerson DJ: The development and validation of the Edinburgh Knee Knee Function Scale: a simple tool for outcome assessment in non-surgical patients. Knee 1999, 6: I I5-123.

32. Irrgang JJ, Snyder-Mackler L, Wainner RS, Fu FH, Harner CD: Development of a patient-reported measure of function of the knee. J Bone Joint Surg Am 1998, 80-A: I I32-I I 45.

\section{Publish with Bio Med Central and every} scientist can read your work free of charge

"BioMed Central will be the most significant development for disseminating the results of biomedical research in our lifetime. "

Sir Paul Nurse, Cancer Research UK

Your research papers will be:

- available free of charge to the entire biomedical community

- peer reviewed and published immediately upon acceptance

- cited in PubMed and archived on PubMed Central

- yours - you keep the copyright
BioMedcentral 